13

\title{
Влияние низкотемпературного надбарьерного слоя GaN на концентрацию электронов в гетероструктуре AIGaN/GaN
}

\author{
(ㄱ А.А. Андреев, Е.А. Вавилова, И.С. Езубченко, М.Л. Занавескин, И.О. Майборода \\ Национальный исследовательский центр „Курчатовский институт“, \\ 123182 Москва, Россия \\ I e-mail: ezivan9@gmail.com
}

(Поступило в Редакцию 27 декабря 2016 г.)

\begin{abstract}
Было изучено влияние низкотемпературных пассивирующих слоев $\mathrm{GaN}$ на электрофизические характеристики двумерного электронного газа (ДЭГ) в гетероструктурах для транзисторов с высокой подвижностью электронов (HEMT). Установлено, что тонкие слои $\mathrm{GaN}$, осажденные in situ при температуре $550^{\circ} \mathrm{C}$, не проявляют полярных свойств и не меняют концентрацию носителей в ДЭГ. При этом аналогичные слои $\mathrm{GaN}$, осажденные при $830^{\circ} \mathrm{C}$, снижают концентрацию носителей в ДЭГ в соответствии с теоретическими расчетами. С помощью дифракции быстрых отраженных электронов установлено, что данный эффект может быть обусловлен различием в структуре и морфологии пленок $\mathrm{GaN}$, осаждаемых при различных температурах.
\end{abstract}

DOI: $10.21883 / J T F .2017 .08 .44742 .2152$

На сегодняшний день транзисторы с высокой подвижностью электронов на основе системы $\mathrm{AlGaN} / \mathrm{GaN}$ являются объектом интенсивных исследований благодаря перспективам их применения в мощных СВЧ устройствах [1,2]. Неизбежное наличие в гетероструктуре $\mathrm{AlGaN} / \mathrm{GaN}$ активных поверхностных состояний ограничивает возможности устройств, приводя к эффекту коллапса тока, снижению пробойного напряжения между стоком и затвором, высоким токам утечки затвора [3-5]. Эффективным способом борьбы с негативными поверхностными эффектами является формирование тонких пассивирующих слоев диэлектриков $\mathrm{SiO}_{2}, \mathrm{Al}_{2} \mathrm{O}_{3}$, $\mathrm{Si}_{3} \mathrm{~N}_{4}$ и других [6-9].

Привлекательным является использование в качестве пассивирующего слоя GaN. Во-первых, его формирование может происходить in situ без извлечения гетероструктуры в атмосферу. Во-вторых, пассивация $\mathrm{GaN}$ не требует проведения модификации заводского оборудования или использования дополнительных материалов при in situ росте пассивационных слоев. Основной проблемой при формировании $\mathrm{GaN}$ является снижение концентрации электронов в двумерном канале [10]. В работе [11] было показано, что надбарьерные слои (cap-layer) $\mathrm{GaN}$, осажденные при температурах порядка $500^{\circ} \mathrm{C}$, эффективно подавляют эффект коллапса тока. Однако ключевым вопросом остается влияние низкотемпературного $\mathrm{GaN}$ на концентрацию электронов, которое определяет эффективность его использования в качестве пассивирующего слоя при росте гетероструктур, особенно с тонкими барьерными слоями. В настоящей работе исследовалась зависимость концентрации электронов в двумерном электроном газе от температуры роста и толщины надбарьерного слоя $\mathrm{GaN}$.

Рост гетероструктур проводился в установке аммиачной молекулярно-лучевой эпитаксии STE3N* фирмы SemiTEq. Гетроструктуры формировались на $50 \mathrm{~mm}$ подложках эпиполированного $c$-ориентированного синтетического корунда $\mathrm{Al}_{2} \mathrm{O}_{3}$ (сапфира). Перед ростом гетероструктуры подложка подвергалась отжигу в высоком вакууме при температуре $850^{\circ} \mathrm{C}$, с последующей нитридизацией поверхности сапфира в потоке аммиака $30 \mathrm{sccm}$ в течение $40 \mathrm{~min}$.

Для изучения влияния пассивации $\mathrm{GaN}$ были выращены пять аналогичных гетероструктур, отличающихся только условиями осаждения завершающего надбарьерного слоя GaN. Структуры состояли из буферного слоя $\mathrm{AlGaN}$ с общей толщиной $550 \mathrm{~nm}$, в котором мольная доля AIN плавно опускалась с толщиной от 100\% до нуля [12]. Далее осаждался канальный слой $\mathrm{GaN}$ толщиной $500 \mathrm{~nm}$. Барьерный слой гетероструктур состоял из спейсер-слоя $\mathrm{AlN}$ толщиной $1 \mathrm{~nm}$ и слоя $\mathrm{Al}_{0.3} \mathrm{Ga}_{0.7} \mathrm{~N}$ толщиной $14 \mathrm{~nm}$. Рост канального и барьерного слоев проводился при температуре $830^{\circ} \mathrm{C}$. Надбарьерные слои $\mathrm{GaN}$ с толщинами 5 и $10 \mathrm{~nm}$ осаждались при температуpax 550 и $830^{\circ} \mathrm{C}$ (образцы A, B, C и D в таблице). Также был выращен образец без надрабрьерного слоя $\mathrm{GaN}$ (образец Е в таблице). Гетероструктуры и надбарьерные слои осаждались при потоке аммиака $200 \mathrm{sccm}$. Значения концентрации и подвижности электронов в двумерном канале были получены четырехзондовым методом Вандер-Пау и приведены в таблице. Морфология поверхности образцов исследовалась при помощи методов дифракции быстрых отраженных электронов (RHEED).

Картина дифракции для образцов А, В и Е имела одинаковый вид (рис. 1,a) и состояла из острых линейных рефлексов, что говорит о гладкой поверхности и монокристаллической структуре полученных пленок. Для низкотемпературных пленок $\mathrm{GaN}$ на образцах $\mathrm{C}$ и D картина дифракции состояла из отдельных точечных рефлексов (рис. $1, b)$. Подобная картина дифракции указывает на то, что низкотемпературные надбарьерные слои $\mathrm{GaN}$ состояли из кристаллитов малого объема. 
Параметры образцов и результаты электрофизических измерений

\begin{tabular}{c|c|c|c|c}
\hline Образец & $\begin{array}{c}\text { Температура слоя } \\
\text { надбарьерного } \\
\text { слоя GaN, }{ }^{\circ} \mathrm{C}\end{array}$ & $\begin{array}{c}\text { Толщина } \\
\text { надбарьерного } \\
\text { слоя GaN, mm }\end{array}$ & $\begin{array}{c}\text { Концентрация } \\
\text { носителей в двумерном } \\
\text { канале, mm }\end{array}$ & $\begin{array}{c}\text { Подвижность, } \\
\mathrm{cm}^{2} / \mathrm{V} \cdot \mathrm{s}\end{array}$ \\
\hline $\mathrm{A}$ & 830 & 5 & $0.7 \cdot 10^{13}$ & 1400 \\
$\mathrm{~B}$ & 830 & 10 & $0.6 \cdot 10^{13}$ & 1517 \\
$\mathrm{C}$ & 550 & 5 & $1.08 \cdot 10^{13}$ & 1636 \\
$\mathrm{D}$ & 550 & 10 & $1.08 \cdot 10^{13}$ & 1654 \\
$\mathrm{E}$ & - & - & $1.1 \cdot 10^{13}$ & 1506
\end{tabular}

Значения концентрации носителей заряда в ДЭГ для полученных образцов представлены на графике (рис. 2)
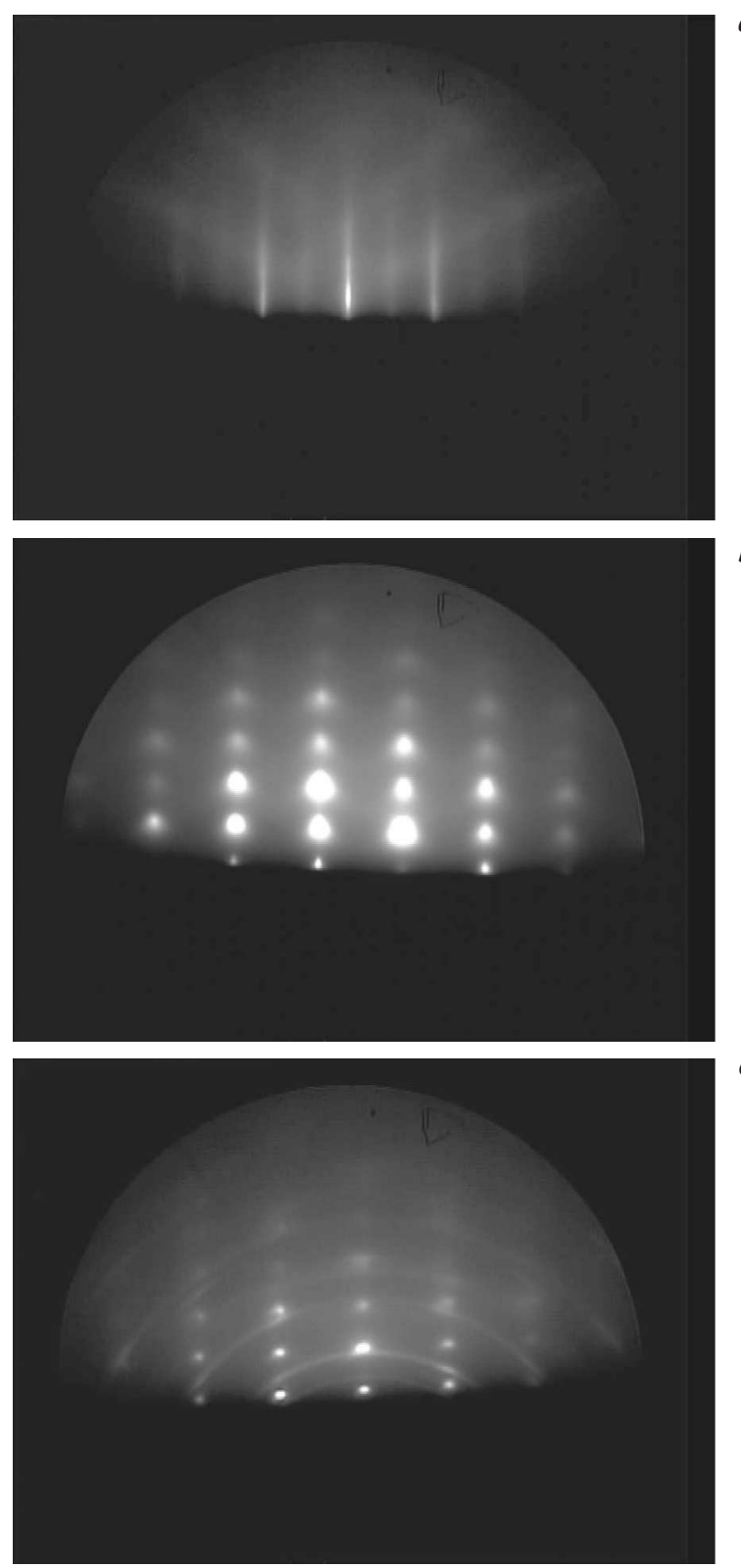

Рис. 1. Дифракция: $a-$ высокотемпературный слой $\mathrm{GaN}$, $10 \mathrm{~nm} ; b-$ низкотемпературный слой $\mathrm{GaN}, 10 \mathrm{~nm} ; c-$ низкотемпературный слой $\mathrm{GaN}$ толщиной $200 \mathrm{~nm}$. в зависимости от толщины надбарьерного слоя GaN. Так же на графике представлены расчетные значения концентрации электронов в проводящем канале, полученные с помощью программного комплекса 1D Poisson Solver [13]. При расчетах значение поверхностного потенциала гетероструктуры было задано так, чтобы расчетные значения концентрации электронов в ДЭГ модельной гетероструктуры, аналогичной образцу Е без надбарьерного слоя, совпадали с экспериментальным значением концентрации для образца Е. Поскольку высота барьера имеет различную величину для $\mathrm{GaN}$ и $\mathrm{AlGaN}$, в расчетную модель структуры без надбарьерного слоя был добавлен виртуальный слой $\mathrm{GaN}$ толщиной $0.2 \mathrm{~nm}$, влияние которого на концентрацию носителей в ДЭГ пренебрежимо мало.

Как видно из графика, для высокотемпературных слоев $\mathrm{GaN}$ наблюдается снижение концентрации носителей в ДЭГ с увеличением толщины слоя GaN. При этом экспериментальные точки находятся в хорошем согласии с результатами численных расчетов концентрации. Так же из графика видно, что надбарьерные слои $\mathrm{GaN}$, осажденные при температуре $550^{\circ} \mathrm{C}$, не оказывают влияния на концентрацию носителей в ДЭГ.

Рассмотрим механизм влияния надбарьерного слоя $\mathrm{GaN}$ на концентрацию электронов в ДЭГ. На рис. 3, $а$ показана зонная диаграмма гетероперехода

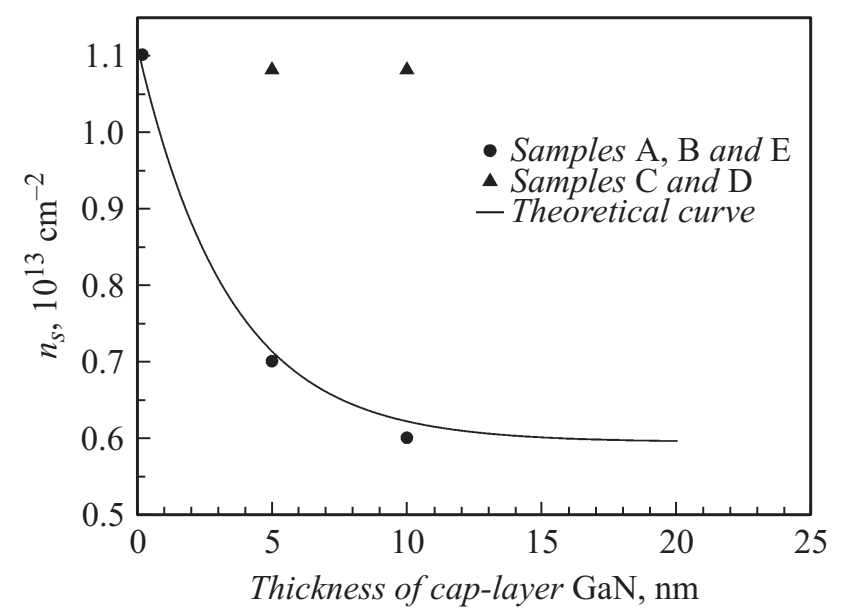

Рис. 2. Зависимость концентрации электронов в двумерном канале от толщины надбарьерного слоя $\mathrm{GaN}$. 

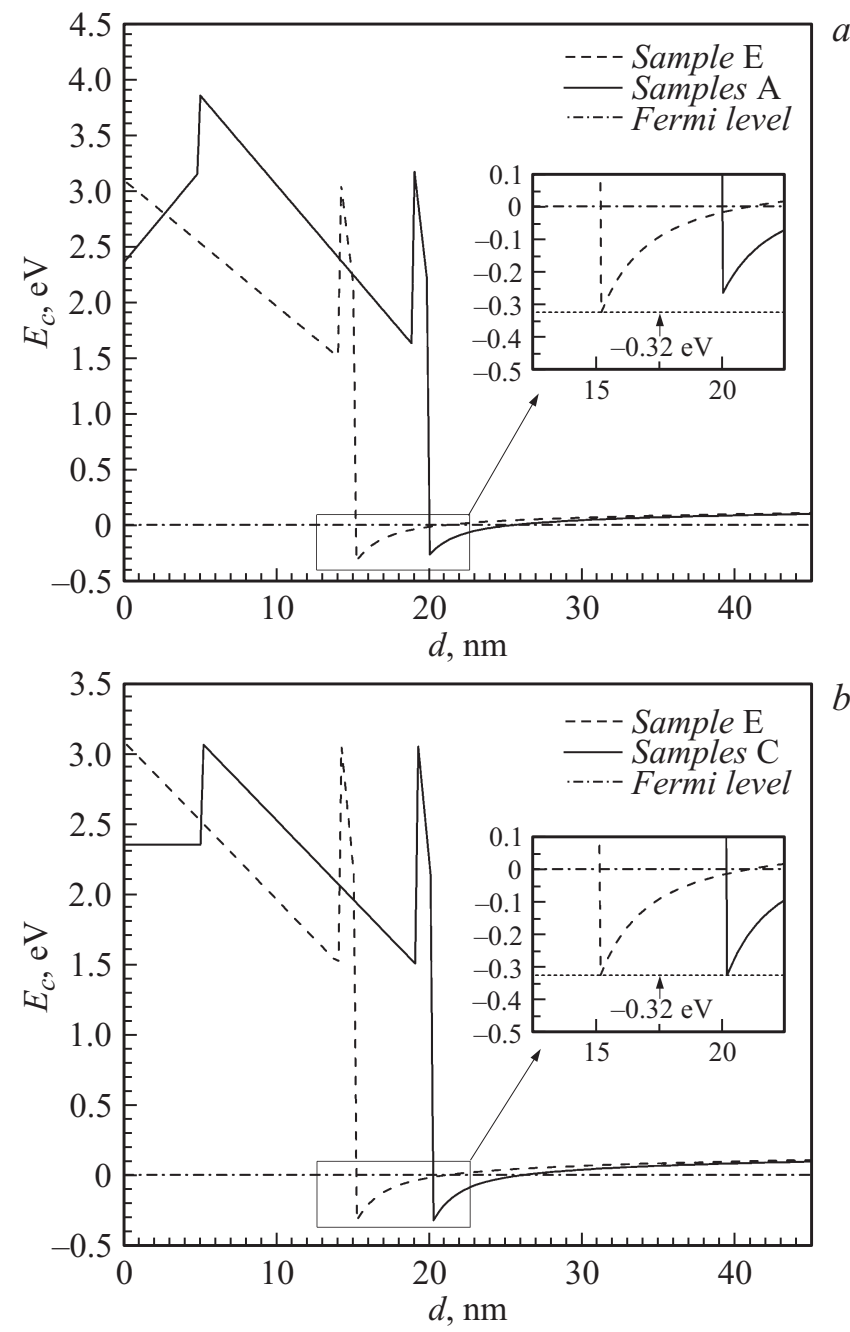

Рис. 3. $a-$ зонная диаграмма дна зоны проводимости для образцов А (сплошная линия) и Е (штриховая линия); $b-$ зонная диаграмма дна зоны проводимости для образцов С (сплошная линия) и Е (штриховая линия). Пунктирная линия - дно квантовой ямы для образца Е.

$\mathrm{AlGaN} / \mathrm{AlN} / \mathrm{GaN}$ с надбарьерным слоем $\mathrm{GaN}$ и без него. За счет эффекта спонтанной поляризации в монокристаллических слоях $\mathrm{GaN}$ присутствуют встроенные электростатические поля, что приводит к снижению концентрации носителей в ДЭГ за счет уменьшения глубины квантовой ямы. Из результатов, полученных для образцов $\mathrm{C}$ и $\mathrm{D}$, следует, что низкотемпературные надбарьерные слои $\mathrm{GaN}$ не влияют на концентрацию носителей в ДЭГ, т.е. не проявляют поляризационных свойств, в отличие от горячих слоев $\mathrm{GaN}$ на образцах А и $\mathrm{B}$ (рис. $3, b$ ). Таким образом, пленки $\mathrm{GaN}$, выращенные при разных температурах, не только имеют различную морфологию, но и проявляют различные поляризационные свойства.

Для получения дополнительной информации о морфологии низкотемпературных слоев при температуре $550^{\circ} \mathrm{C}$ была выращена пленка $\mathrm{GaN}$ толщиной $200 \mathrm{~nm}$ (условия роста аналогичны образцам C и D). При наблюдение RHEED в процессе роста низкотемпературного слоя $\mathrm{GaN}$ по характерной дифракционной картине в виде колец Дебая было обнаружено наличие поликристаллической фазы (рис. 1,c). Поликристаллическая структура могла бы объяснить ее неполярные свойства низкотемпературных слоев $\mathrm{GaN}$ взаимной компенсацией разнонаправленных дипольных моментов отдельных кристаллитов, однако на картине дифракции также наблюдались интенсивные дифракционные максимумы, соответствующие $c$-ориентированным кристаллитам $\mathrm{GaN}$. Можно заключить, что неполярные свойства слоев низкотемпературных слоев $\mathrm{GaN}$, вероятно, связаны с особенностями их кристаллической структуры, но механизм подавления поляризационных свойств пока что не ясен и требует дальнейших исследований. Вместе с тем неполярный характер низкотемпературных слоев $\mathrm{GaN}$ в сочетании с продемонстрированной другими исследователями способностью подавлять эффект коллапса тока [11] делает их привлекательными в качестве защитных пассивирующих слоев для нитридных НЕМТ-структур.

Таким образом, в настоящей работе было проведено исследование низкотемпературных и высокотемпературных надбарьерных слоев $\mathrm{GaN}$ и сравнение их влияния на концентрацию электронов в ДЭГ гетероструктур для НЕМТ. В результате установлено, что низкотемпературные слои $\mathrm{GaN}$, выращенные при $550^{\circ} \mathrm{C}$, не проявляют полярных свойств в отличие от слоев, выращенных при $830^{\circ} \mathrm{C}$, что, по-видимому, обусловлено различием в структуре пленок, выращенных при разной температуре.

Работа выполнена при финансовой поддержке Министерства образования и науки РФ (соглашение № 14.607.21.0116 от 14.10.2015, RFMEFI60715X0116).

\section{Список литературы}

[1] Nanjo T., Imai A., Suzuki Y., Abe Y., Oishi T., Suita M., Yagyu E., Tokuda Y. // IEEE Trans. Electr. Dev. 2013. Vol. 60. N 3. P. 1046.

[2] Chung J.W. et al. // IEEE Electr. Dev. Lett. 2010. Vol. 31. N 3. P. 195.

[3] Vetury R., Zhang N.Q., Keller S., Mishra U.K. // IEEE Trans. Electr. Dev. 2001. Vol. 48. N 3. P. 560.

[4] Ohno Y., Nakao T., Kishimoto S., Maezawa K., Mizutani T. // Appl. Phys. Lett. 2004. Vol. 84. N 12. P. 2184.

[5] Tan W.S., Houston P.A., Parbrook P.J., Wood D.A., Hill G., Whitehouse C.R. // Appl. Phys. Lett. 2002. Vol. 80. N 17. P. 3207.

[6] Arulkumaran S., Egawa T., Ishikawa H., Jimbo T., Sano Y. // Appl. Phys. Lett. 2004. Vol. 84. P. 613.

[7] Wang C., Cho S.-J., Kim N.-Y. // Microelectronic Engineer. 2013. Vol. 109. P. 24.

[8] Kim D.H., Kumar V., Chen G., Dabiran A.M., Wowchak A.M., Osinsky A., Adesida I. // Electron. Lett. 2007. Vol. 43. N 2. P. 127.

[9] Sheng Z., Ke W., Le Y., Guo-Guo L., Sen H., Xin-Hua W., Lei P., Ying-Kui Z., Yan-Kui L., Xiao-Hua M., Bing S., XinYu L. // Chin. Phys. B. 2015. Vol. 24. N 11. P. 117307. 
[10] Ambacher O., Foutz B., Smart J., Shealy J.R., Weimann N.G., Chu K., Murphy M., Sierakowski A.J., Schaff W.J., Eastman L.F., Dimitrov R., Mitchell A., Stutzmann M. // J. Appl. Phys. 2000. Vol. 87. P. 334.

[11] Waki E., Deguchi T., Nakagawa A., Egawa T. // Appl. Phys. Lett. 2008. Vol. 92. P. 103507.

[12] Андреев А.А., Грищенко Ю.В., Езубченко И.С., Занавескин М.Л., Майборода И.О., Рудик М.А., Федоров Ю.В. // Журнал радиоэлектроники. 2015. Т. 1.

[13] G. Snider // http://www3.nd.edu/ gsnider 